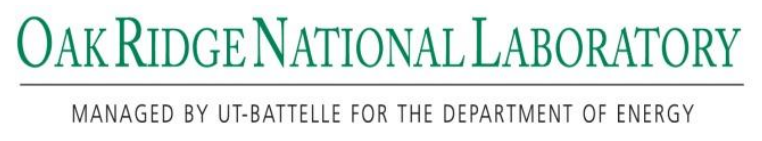

ORNL/TM - 2012/20

\title{
Use of Textured Surfaces to Mitigate Sliding Friction and Wear of Lubricated and Non-Lubricated Contacts
}

An annotated literature review

Peter Blau

Oak Ridge National Laboratory

\author{
Prepared by \\ Oak Ridge National Laboratory \\ Oak Ridge, TN 37831 \\ Managed by \\ UT-BATTELE, LLC \\ for the \\ U.S. Department of Energy \\ Under contract DE-AC05-00PR2225 \\ DATE \\ Approved for \\ Unlimited Distribution
}

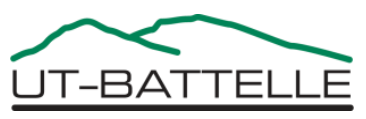




\section{DOCUMENT AVAILABILITY}

Reports produced after January 1, 1996, are generally available free via the U.S. Department of Energy (DOE) Information Bridge.

Web site http://www.osti.gov/bridge

Reports produced before January 1, 1996, may be purchased by members of the public from the following source.

National Technical Information Service

5285 Port Royal Road

Springfield, VA 22161

Telephone 703-605-6000 (1-800-553-6847)

TDD 703-487-4639

Fax 703-605-6900

E-mail info@ntis.gov

Web site http://www.ntis.gov/support/ordernowabout.htm

Reports are available to DOE employees, DOE contractors, Energy Technology Data Exchange (ETDE) representatives, and International Nuclear Information System (INIS) representatives from the following source.

Office of Scientific and Technical Information

P.O. Box 62

Oak Ridge, TN 37831

Telephone 865-576-8401

Fax 865-576-5728

E-mail reports@osti.gov

Web site http://www.osti.gov/contact.html

This report was prepared as an account of work sponsored by an agency of the United States Government. Neither the United States Government nor any agency thereof, nor any of their employees, makes any warranty, express or implied, or assumes any legal liability or responsibility for the accuracy, completeness, or usefulness of any information, apparatus, product, or process disclosed, or represents that its use would not infringe privately owned rights. Reference herein to any specific commercial product, process, or service by trade name, trademark, manufacturer, or otherwise, does not necessarily constitute or imply its endorsement, recommendation, or favoring by the United States Government or any agency thereof. The views and opinions of authors expressed herein do not necessarily state or reflect those of the United States Government or any agency thereof. 


\section{Use of Textured Surfaces to Mitigate Sliding Friction and Wear of Lubricated and Non-Lubricated Contacts}

An annotated literature review

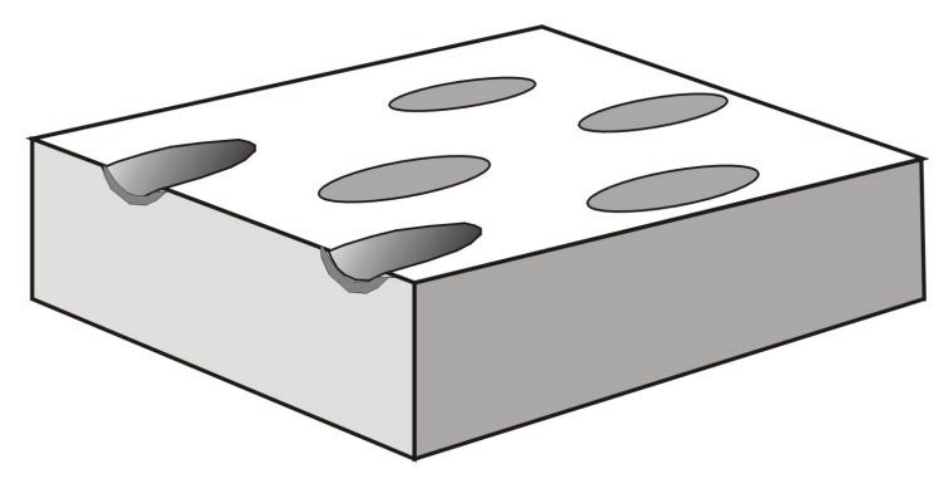

Peter Blau

Materials Science and Technology Division

Oak Ridge National Laboratory 



\section{Foreword}

This report consists of both a review of the tribology literature and a short summary of past studies at ORNL concerning how the macro and micro-geometry of surfaces can be modified to affect changes in frictional behavior, particularly under lubricated conditions. It was prepared in conjunction with an on-going project entitled "Friction reduction through surface modification." The overall purpose of the work is to improve the fuel efficiency of diesel-powered vehicles by employing patterns of micro-scale features to reduce the sliding friction between contacting surfaces in engines. Funding was provided by the U.S. Department of Energy (DOE), Office of Energy Efficiency and Renewable Energy, Office of Vehicle Technologies, under the Heavy Vehicle Propulsion Materials program, managed by Jerry Gibbs. No proprietary data or other commercially-sensitive information has been included. 



\section{CONTENTS}

Abstract

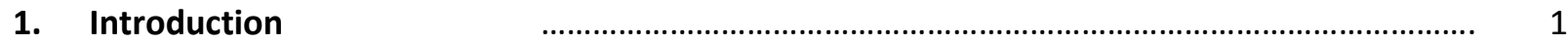

2. Attributes of Textured Surfaces

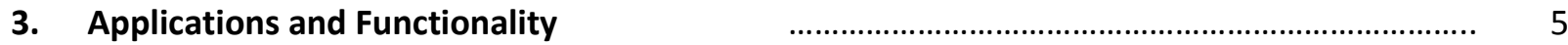

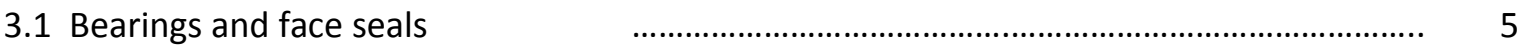

3.2 Biomaterials applications

3.3 Debris trapping

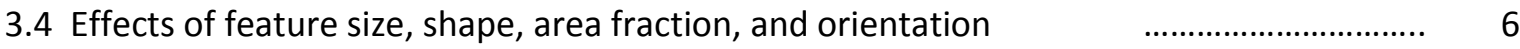

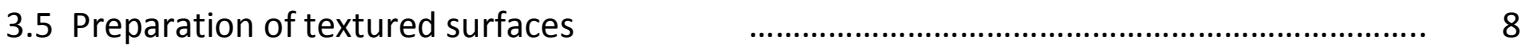

3.5.1 Laser surface texturing studies $\quad$........................................................... 8

3.5.2 Textured surfaces containing solid lubricants $\quad$........................................ 10

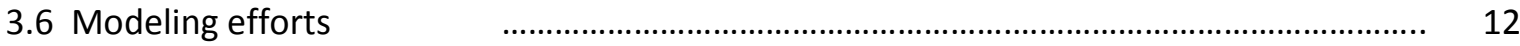

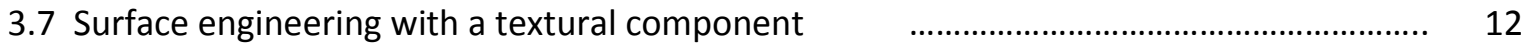

4. Conclusions

5. References

Appendix A: Basic and Applied Research on Texturing for Improved Friction and Wear $\quad \ldots . . . . \quad 15$ 



\begin{abstract}
If properly employed, the placement of three-dimensional feature patterns, also referred to as textures, on relatively-moving, load-bearing surfaces can be beneficial to their friction and wear characteristics. For example, geometric patterns can function as lubricant supply channels or depressions in which to trap debris. They can also alter lubricant flow in a manner that produces thicker load-bearing films locally. Considering the area occupied by solid areas and spaces, textures also change the load distribution on surfaces. At least ten different attributes of textures can be specified, and their combinations offer wide latitude in surface engineering. By employing directional machining and grinding procedures, texturing has been used on bearings and seals for well over a half century, and the size scales of texturing vary widely.

This report summarizes past work on the texturing of load-bearing surfaces, including past research on laser surface dimpling of ceramics done at ORNL. Textured surfaces generally show most pronounced effects when they are used in conformal or nearly conformal contacts, like that in face seals. Combining textures with other forms of surface modification and lubrication methods can offer additional benefits in surface engineering for tribology. As the literature and past work at ORNL shows, texturing does not always provide benefits. Rather, the selected pattern and arrangement of features must be matched to characteristics of the proposed application, bearing materials, and lubricants.
\end{abstract}





\section{Introduction}

In the field of materials science, the term 'texture' is used to refer to the preferred orientation of crystalline grains within a material. In machining science and surface metrology it is used to refer to the roughness, waviness, and lay (directionality) of surface features. Like other forms of surface treatment, the reasons for applying textures spans from cosmetic appearance to optical qualities, and from compatibility with human body environments (implants) to the control of lubrication.

In tribology, the current context, the term texture will refer to the form, dimensions, and patterning of a surface as well as the associated effects produced on the underlying material. Some of the characteristics of textured surfaces arise by design, but some, like processing artifacts (e.g., upset ridges, micro-cracks, subsurface work-hardened areas), result from the methods that are used to produce those patterns. In tribology, the four basic functions of texturing are:

(i) to alter the flow and film thickness of lubricating fluids locally and across the contact region,

(ii) to serve as channels to supply lubricant to a surface

(ii) to trap debris that would otherwise become embedded or abrade the surfaces, and

(iii) to alter the bearing pressure distribution.

Engineers have long applied geometric features to lubricated solid surfaces in order to control friction and wear (i.e., even for centuries, if the definition of 'engineered surfaces' is extended to include millstones and the like). Owing to advances in materials and processing, the variety of the patterns and the methods used to produce them have evolved greatly. Likewise, computer-based models to portray the effects of textured surfaces on contact stresses, lubricant film thickness, and friction have become more rigorous and physically realistic.

It is well-known that friction reduction of moving parts of internal combustion engines improves efficiency and fuel economy. Therefore, it is important to consider all friction control options when designing internal rubbing surfaces. These include improved lubricants, improved design of mating parts, use of coatings and surface treatments, and the texturing of surfaces. The control of surface finishes and machining processes like plateau-honing have long been used to improve bearing performance, but the present project emphasizes approaches that go beyond the considerations of roughness, waviness, and lay that are associated with traditional machining.

Various terms have been used to describe the intentional synthesis of periodic geometric features on a bearing surface. These include textured surfaces, patterned surfaces, and modulated surfaces. Such surfaces can be designed with an endless variety of features, as will be described. Some are round, some are sharp, some are shallow, and some are relatively deep. Some features are discontinuous, like dimples, pores, and separated shapes. Others are continuous, like grooves and cross-hatched patterns whose valleys and peaks run completely across the contact surface. Another consideration is whether one or both mating surfaces are patterned. It may be neither necessary nor desirable to pattern both counterfaces.

As will be discussed subsequently, geometric surface texturing is only one aspect of surface engineering. In fact, microstructure design, coatings, or compositional surface engineering can be combined with geometric texturing to provide further friction and wear benefits. 


\section{Attributes of Textured Surfaces}

As mentioned above, textured surfaces have geometric and microstructural attributes. These attributes are generally larger in scale than the surface finish of a typical bearing or gear (typically from 0.025-0.3 $\mu \mathrm{m}$ in arithmetic roughness [1]), but in special cases they can be only a few $\mathrm{nm}$ in size. Several attributes of textured surfaces are depicted in Figure 1. They can be categorized as follows:

- Individual feature shape(s), including the depth profiles of the cavities [2]

- Individual feature dimensions

- Asymmetry of patterns and features (aspect ratio)

- Orientation of the features relative to the lubricant supply

- Orientation of the features relative to the direction of relative motion with the counterface

- Whether one or both mating surfaces are textured

- Feature spacing relative to adjacent features

- Fraction or percentage of the apparent contact area occupied by features

- Mixtures of feature shapes versus similar shapes throughout the pattern

- Artifacts such as edge ridges or subsurface 'affected zones'

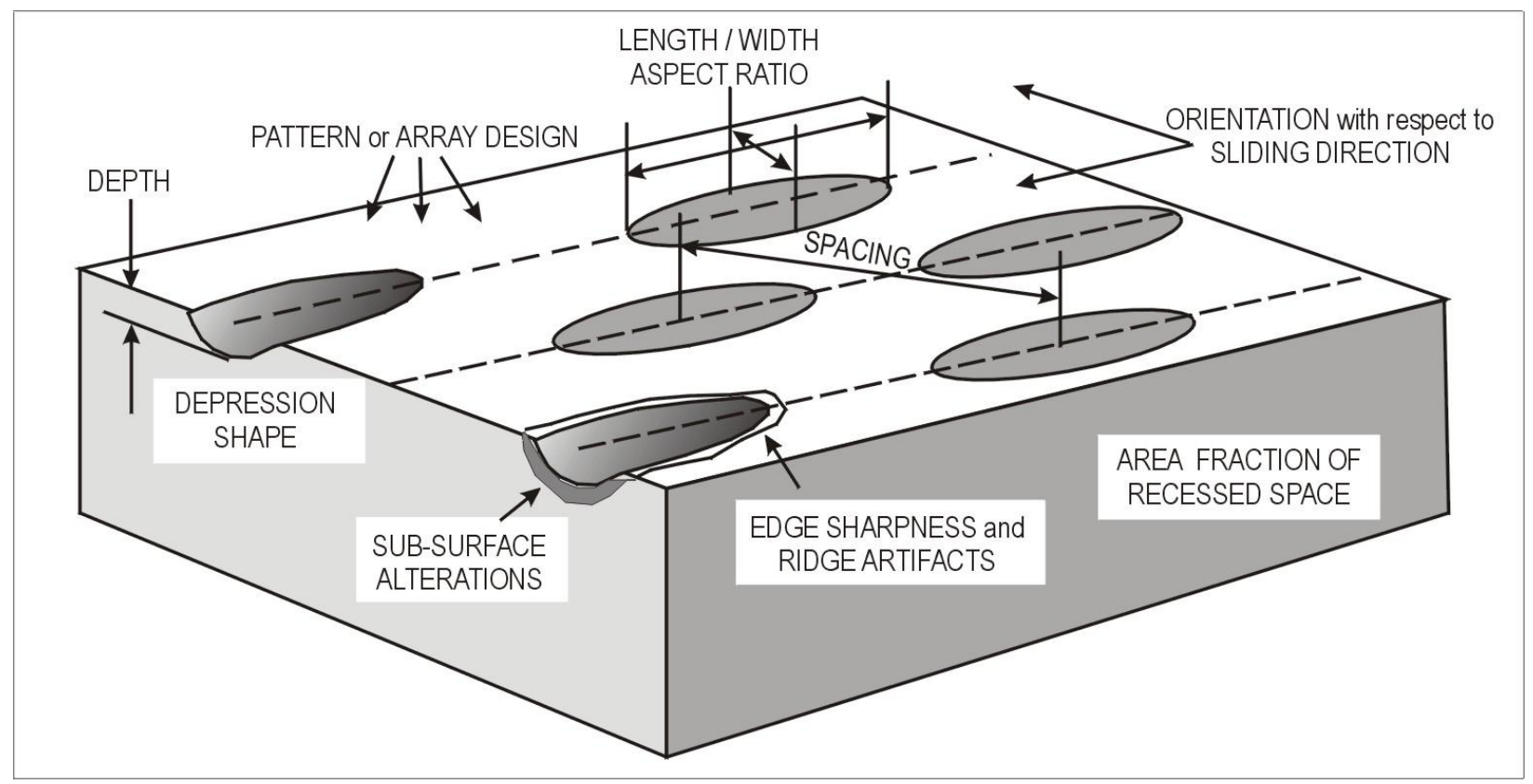

Figure 1. Some attributes of textured surfaces.

As exemplified in Figure 1, an enormous number of possibilities exist to optimize texture-based surface engineering of tribosystems. Numerous combinations of feature shapes, sizes, and orientations are possible. Furthermore, one should distinguish between intentional geometric features and artifacts that result from the texturing process. For example, Figure 2 shows an optical image of an array of Vickers impressions on CDA 932 bearing bronze, and Figure 3 shows a 3D vertical scanning interferometric 
image (VSI) of two impressions. Color-coded by feature height, it shows that indentation texturing of a surface can raise hills of material adjacent to it. In this case, the upset areas required further polishing to produce a flat surface with an array of negative features. Data in Figure 4 indicate that the height of the plastically deformed, raised edge on indentations (h) tends toward about $14 \%$ of the depth of the impression ( $z$ ), and is nearly independently of the applied load, if the load exceeds $\sim 100$ grams-force. Other types of process-related artifacts, like cracks or pits, can also arise on brittle materials, as will be discussed in Section 3.5 in the context of laser surface dimpling.

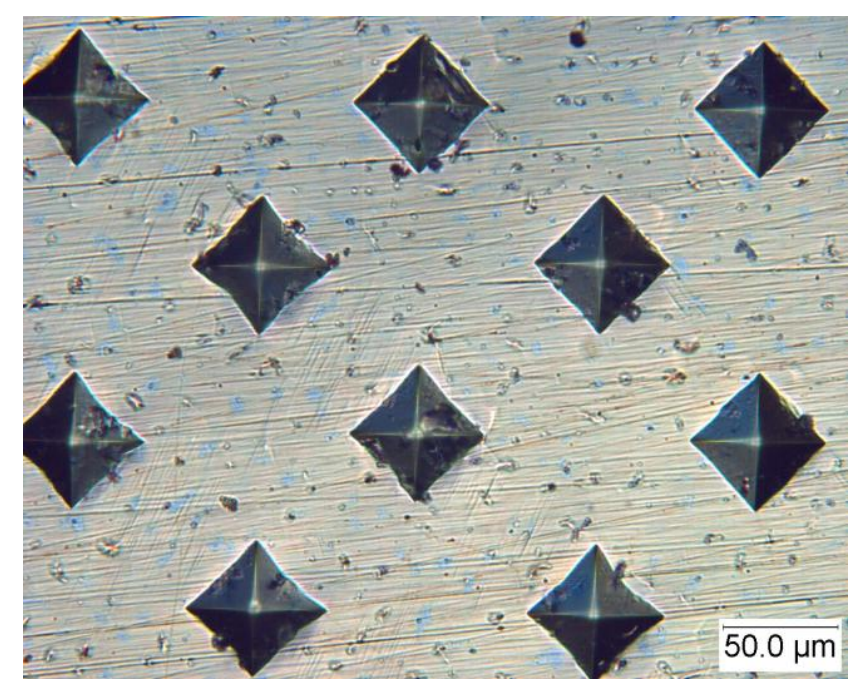

Figure 2. Array of Vickers microindentation impressions placed $0.150 \mathrm{~mm}$ apart to form a textured surface on bearing bronze (as-indented).

Since empirical testing of the countless variations of patterned features is economically impractical, practical guidelines for the selection of patterns and attributes for specific bearing configurations are essential. Some of these can involve sophisticated computer models, as described later. In fact, international working groups have been formed to address the issue [3].

The present report presents an overview of past research on the texturing of bearing surfaces to control friction and wear. It begins with relatively macroscale approaches and concludes with a discussion of finer-scale features and techniques. For convenience, Appendix A provides a list of texturing references sorted by approach and application, with particular mention of applications in automotive engines. 


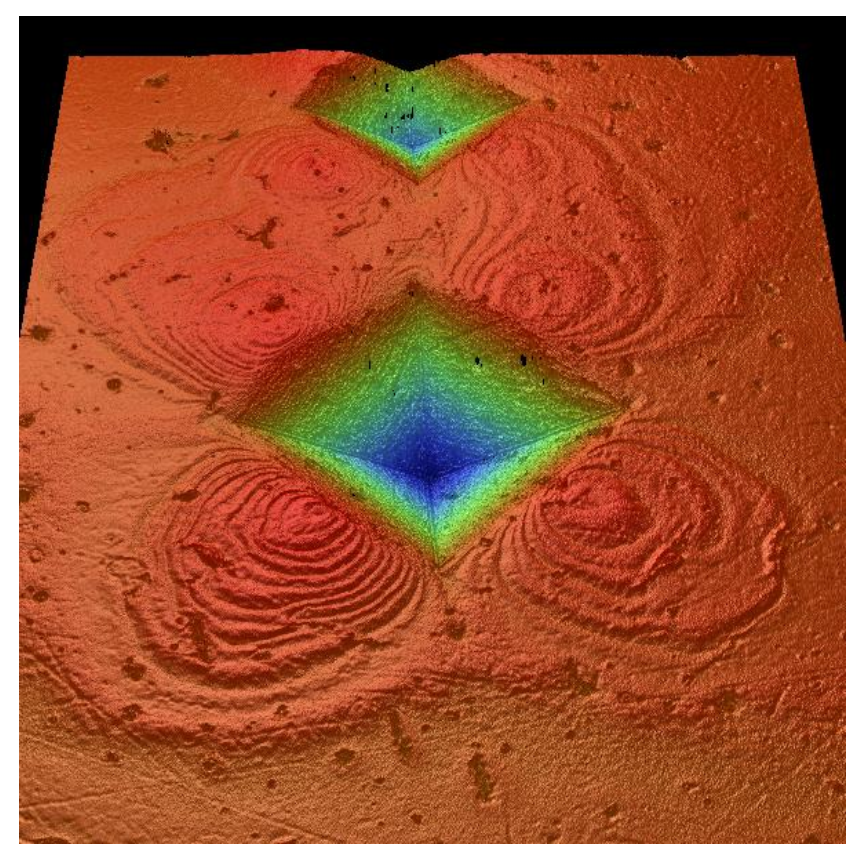

Figure 3. VSI 3D topographic image of Vickers impressions in bronze showing raised ridges due to material displacement. (Bottom impression: $200 \mathrm{~g}$-f load, top impression: $100 \mathrm{~g}$-f load).

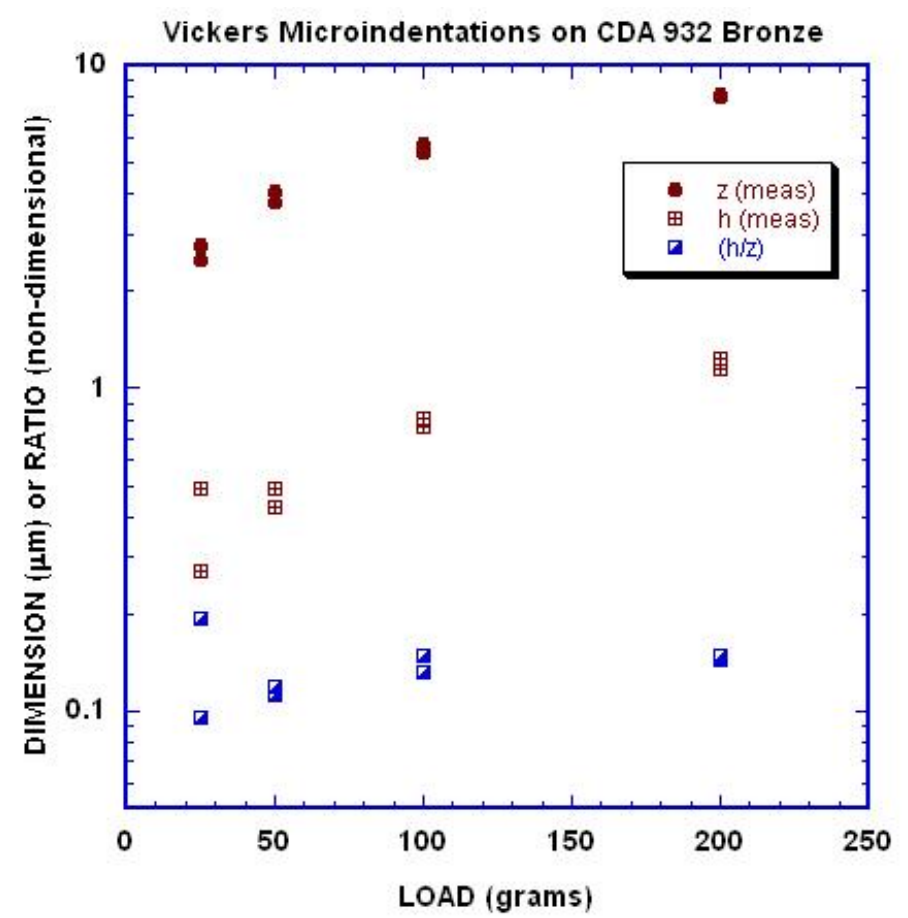

Figure 4. Comparison of the depth of the indentations $(z)$ in bronze to the height of the ridge $(h)$ surrounding the impression (two of the impressions are shown in Figure 2 ). The $(\mathrm{h} / \mathrm{z})$ ratio is relatively constant at the higher loads. 


\section{Applications and Functionality}

Surface engineering of textures for tribological applications is system-specific. This section reviews some common applications for textured bearing surfaces, how their attributes can affect friction in wear, and the ways in which they are produced.

3.1 Bearings and face seals. The early, macro-scale work tended to address the supply of the lubricants to the contact surface and the removal of wear debris. More recent texturing work has included considerations like the micromechanics of altering the asperity scale lubrication regime and shifting the Stribeck curve toward the origin to enable thicker films (higher film thickness to roughness ratios) to lower sliding speeds and oil viscosities [4]. Applications of grooves and feed channels of various types were used, for example, in journal bearings [5] and face seals [6] for over a half century. Designs have utilized a wide range of patterns and shapes, including smooth and continuous grooves [7] and chevronlike ('herringbone') features [8]. The groove-like features are symmetrical or non-symmetrical [9] depending upon the desired effect on distributing the lubricant.

Oui and Khonsari recently modeled the effects of spherical dimples on the load-carrying capacity, leakage, and film thickness of a face seal configuration [10]. Modern approaches generally utilize much finer features ( $\mu \mathrm{m}$ to $\mathrm{nm}$ ) than the early plain bearing grooves $(\mathrm{mm})$, but at the same time, they require better bearing surface alignment to realize their benefits.

SKF engineers have conducted research on the shapes and spacings of dimples to place on rolling elements to decrease the speed required to separate the surfaces and allow the film to support them [11]. Dimpled, golf-ball-like surfaces seem to provide the most-efficient lubrication transport. In addition, the pits on the surface act as lubricant reservoirs, and rolling action transports oil or grease into the inlet of the contact. This work continues, and dimpled ball bearings are likely to find increased applications.

\subsection{Biomaterials applications.}

Textured patterns have been used with varying success to improve the performance of bearing surfaces in human body joint replacements like hips. In joint simulator studies of patterned polyethylene, it was found that the textures could reduce wear by as much as two thirds [12]. Wear can lead to osteolysis (loosening) or the formation of great cells. Commercial processes, like BioSurf ${ }^{\circledR}$ [13] place golf ball-like dimples on implants. In terms of friction, friction reductions of $8-35 \%$ have been reported using nanoimprint lithography [14].

Patterning or texturing does not consistently produce beneficial effects, however. In studies of metal on metal hip implants, the placement of shallow round dimples on the spherical head surface produced a deleterious effect on lubricant film formation $[15,16]$. With conflicting results like these, it cannot be stated that texturing is always beneficial or detrimental in body implants without further qualification of the materials and conditions under which the texturing process is used.

3.3 Debris trapping. Publications as early as 1927 [17] drew attention to the need to control abrasive particles in lubricants. Wear debris and contaminating particles, collectively called 'third bodies', can alter the friction and wear characteristics of bearings, sliding seals, or gears. Williams and Hycica [18] 
showed how the abrasion rate and wear morphology is affected by the abrasive particle diameter relative to the lubricant film thickness. The effects of third bodies therefore depend on their sizes, shapes, and hardness relative to the interface through which they must pass as well as to the film thickness of the lubricant if present.

If particles are extremely small, they could pass through the interface without harm. If they are too large, they can accumulate or jam up in the converging entrance to the contact, or they might flow around the bearing. Particles whose size scale is similar to the clearance (mating surface separation) can be the most problematic. If their concentration becomes too large, they can abrade, embed, or otherwise impede relative motion. Therefore, in most engineering components, third-bodies are deleterious and must be controlled in some way. Filtration and oil changes are one method, but surface texturing is also employed.

The debris trapping role of textured sliding surfaces was discussed in the book by Suh [19] and several published papers on similar work by others in his group [20-22]. Calling them, 'undulated surfaces', he created checkerboard patterns by an etching process and demonstrated their significant friction reductions in unidirectional sliding of bronzes and other alloys. The role of debris trapping during oscillating (fretting) contact of surfaces produced by laser dimpling was discussed later in a paper by Valchock et al. [23]. During lubricated unidirectional sliding, the lubricant film has an opportunity to reach steady state thickness, but during oscillation in which the velocity and direction of motion varies, the effects of texturing are primary manifest in the debris trapping role.

Debris trapping and enhanced lubricating functions were combined in a novel approach described by Sep and Kucaba-Pietal [24]. The approach was to use a soft metal ( $0.8 \mathrm{~mm}$ diameter $\mathrm{Cu}$ wire) placed in spiral grooves around the journal. Owing to the shape of the wire, at both sides of each groove there is a crevice into which debris can be trapped. The wire material also provides a measure of embeddability to avoid hard debris to remain in the bearing interface. The wear of both the journal and the sleeve was significantly reduced in experiments using alumina powder added to the oil.

3.4 Effects of feature size, shape, area fraction, and orientation. Perhaps the coarsest scales of texturing involve the supply of lubricant to a bearing surface. As noted in Section 3.1, grooves and channels in large plain bearings can be the order of millimeters in width and depth, but recent surface processing developments have enabled them to be made much smaller. For example, features of only $4.5 \mathrm{~nm}$ tall were fabricated using argon ion etching of aluminum titanium carbide flying heads (picosliders) intended for use on computer hard disks at a normal flying height of 5-7 nm. The textures significantly reduced the vibrations associated with contact during start and stop cycling, and it it reduced lubricant depletion in the contact. However, the texture height needed to be optimized. Too much height ( $~ 9.5 \mathrm{~nm})$ and the texturing effects were deleterious. [25].

Petterson and Jacobson [26] investigated the effects of differently-sized square pockets and grooves on friction of lubricated silicon substrates coated with hard films. For diamond-like carbon (DLC) films, the texturing did not help because the film needed to form a continuous low friction layer. Thus, the lubricating nature of the DLC film helped more than any debris trapping functions. For these coatings, the smaller-sized squares $(5 \mu \mathrm{m})$ enabled longer periods of low, stable friction compared to larger 50 $\mu \mathrm{m}$ squares. Overall, texturing was not always helpful because it can compete with more effective methods produced by the selected coating. 
The effects of the area fraction of surface coverage on the critical load for transition between low and high friction on SiC face seals were investigated by Wang et al. [27]. Pores $150 \mu \mathrm{m}$ in diameter were produced by a $\mathrm{CO}_{2}$ laser and water was used as the lubricant in a face-seal test apparatus. An optimum of 2.8 area \% proved most effective in increasing the critical load for a transition between lower friction (hydrodynamic lubrication) and higher friction (mixed lubrication) sliding.

The sizes of textured features varies widely depending on the method used to produce them and the contact area to be covered. Fine-scale textures, achieved by ion-etching that raised small islands from 3 to $30 \mathrm{~nm}$ high and from 0.3 to $4 \mu \mathrm{m}$ in length, were placed on the 'sliders' of disk drives in an attempt to reduce stiction [28]. Arrays of 229-548 nm-sized ellipsoidal dimple arrays were produced using a femptosecond laser on silicon surfaces [29]. Studies using lubrication with water indicated up to a factor of 2.6 in friction reduction for the textured surfaces.

In 2003, Hsu [30] provided an overview of the effects of features of various shapes and orientations. He presented results of paraffin oil-lubricated sliding friction experiments at two speeds: 0.023 and 0.23 $\mathrm{m} / \mathrm{s}$, and 1-40 N loads, using circles, triangles, and oval shaped features produced by lithography and etching. Depending on the sliding speed and orientation of the features relative to the sliding direction, the effects on kinetic friction coefficient (COF) were markedly different; namely:

- Circles (low speed): COF increased with increasing load and produced noisy friction traces

- Circles (high speed): COF decreased rapidly with load from 1-5 N, and then remained relatively low and stable.

- Ellipses (sliding parallel to the long axis at low speed): COF increased with increasing load and produced moderately noisy friction traces

- Ellipses (sliding parallel to the long axis at high speed): COF decreased with increasing load from 1-5 $\mathrm{N}$ and produced stable friction traces

- Ellipses (sliding perpendicular to the long axis at low speed): COF increased gradually with increasing load and produced moderately noisy friction traces

- Ellipses (sliding perpendicular to the long axis at high speed): COF decreased with increasing load and produced stable friction traces

Using bearing steel sliding on micro-dimpled silicon nitride plates, Wakuda et al. [31] found that the density of dimples on a surface $(7.5,15$, and $30 \%)$ had a greater effect at higher sliding velocities ( 1.0 $\mathrm{m} / \mathrm{s}$ ) than at relatively low sliding velocities ( $\sim 0.01 \mathrm{~m} / \mathrm{s}$ ). Larger dimples ( $\sim 0 \mu \mathrm{m}$ diameter) showed this effect more than did smaller ones $(\sim 40 \mu \mathrm{m})$. In fact, the lower densities showed greater benefits than the higher density of micro-dimples supposedly because, as the load bearing area decreases, the contact pressure increases and overwhelms the local benefits of lubricant film pressurization.

The effects of velocity and feature shape were explored by Nakano et al. [32] on experiments with cast iron. Grooves actually increased the friction while dimples reduced it. Like the work of Wakuda [31], the friction coefficient effects of dimples were more evident at higher speeds. In later work, Yuan et al. [33] conducted studies on the effects of the angle of microgrooves to the (reciprocating) sliding direction on friction of cast iron containing $100 \mathrm{~mm}$ wide grooves with a $10 \%$ areal density. Grooving, with the sliding direction across or at an incline to the grooves provided friction coefficient reductions of up to $44 \%$. 
Work by Vilhena, et al [34] investigated the effects of dimple depth (5.3-16.5 $\mu \mathrm{m}$ deep) and sliding speed $(0.015$ to $0.45 \mathrm{~m} / \mathrm{s})$ on laser-dimpled bearing steel surfaces using a pin-on-disk tribometer. Polyalphaolefin oil was used as the lubricant under fully-flooded conditions. The effects of having dimples and of the average depth of the dimples on friction reduction were greater at higher sliding speeds, given equal sized dimples and the same dimple spacing.

Features on textured surfaces need not necessarily be dimples, grooves, or depressions. For example, Yoon et al. [35] placed rows of nano-scale projections on polymer surfaces using a soft lithographic technique and observed friction reduction using a specialized tribometer.

3.5 Preparation of textured surfaces. The desired sizes, shapes, and spacing of textures affect the selection of the process. Hsu [30] listed the following methods for producing textured surfaces:

- Engraving

- Indentation

- Lithography

- Electro-discharge machining (EDM)

- Ultrasonic methods

- Laser engraving

In addition to the above, a variety of methods are also available from the electronics and coating industries. Magnetron sputtering and ion beam sputtering [36], abrasive jet cutting [31], and laser dimpling have all been used to produce textures as well. Recent investigators also recognized the effects of the dimpling process on near-edge rims and re-polished the surfaces prior to tribo-testing [33].

3.5.1 Laser Surface Texturing Studies. The U.S. Department of Energy, Office of Transportation Materials, precursor to the Office of Vehicle Technologies, funded research at ORNL during 2002-2004 on the effects of laser surface texturing (LST) of ceramics for friction control [37], while companion work at Argonne National Laboratory [38, 39], using the same approach, was focused on steels. In both cases, dimpled specimens were prepared by I. Etsion of the Technion in Israel (see [4] for a review of his earlier work).

The microstructures and thermal cracking produced by LST in dimpled ceramics were studied, as were the effects of load and speed on friction reduction. Figure 5(a) shows a pattern of laser dimples on zirconia and Figure 5(b) shows a close-up of the thermal cracking that can occur from the high energies and rapid heating and cooling associated with laser dimpling by LST. Figure 6 shows the topographic details of a single dimple. 


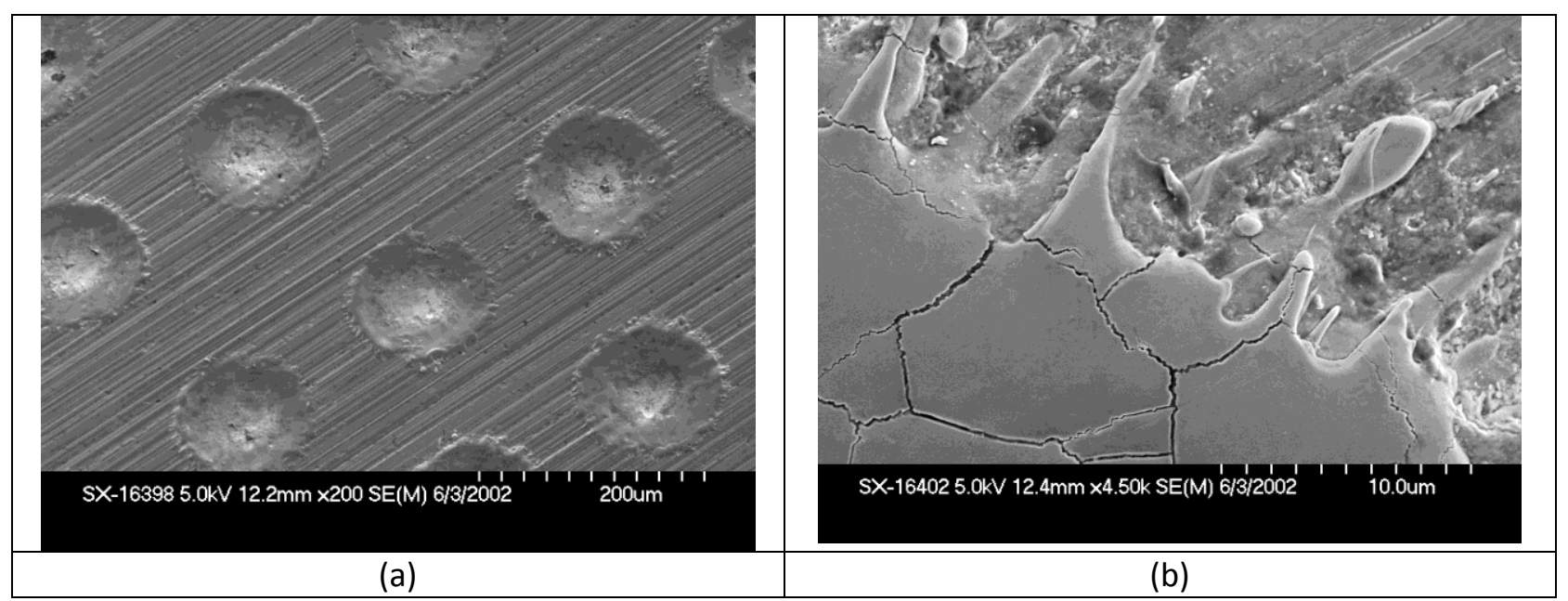

Figure 5. Scanning electron microscope images of laser-dimpled zirconia. (ORNL)

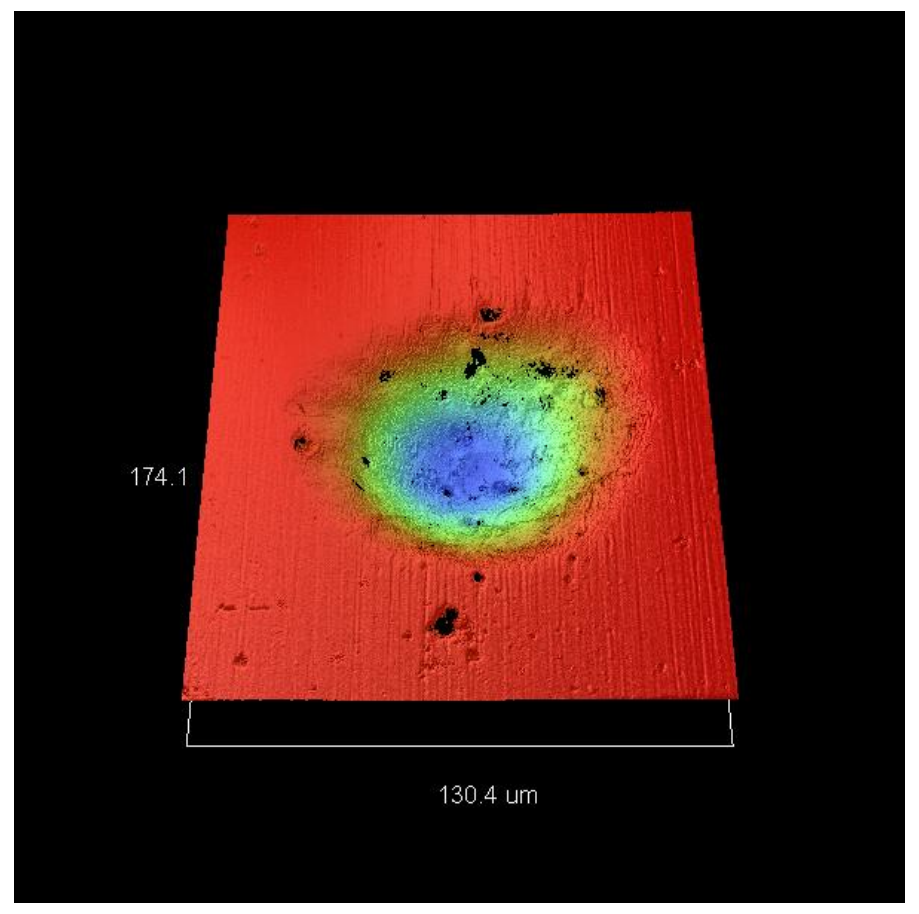

Figure 6. Vertical scanning interferometric 3D image of a dimple on transformation-toughened zirconia, like that shown in Figure 5(a). The depth of the dimple is $10.5 \mathrm{~mm}$ and it is about $104 \mu \mathrm{m}$ in diameter

Figure 7 summarizes the effects of oscillating frequency on the friction of cylindrical reciprocating ceramic pins of transformation-toughened zirconia (TTZ) that had a dimpled contact surface. A crossed cylinder of silicon nitride was slid against it. The specimens had to be aligned very precisely, and the 
ridges on the dimples had to be carefully polished away in order for the effects on friction to be noticed. Still the effects of prior edge ridges can affect the distribution of wear particles between dimples, as shown in Figure 8.

Work on the effects of load and speed on the friction of laser dimpled steels was conducted using pinon-disk experiments at Argonne National Laboratory [38,39]. The effects of dimpling were basically to shift the transition between boundary and mixed film lubrication to a lower value of Sommerfeld number. The implications of this were that the friction coefficient could be reduced at either lower speeds, higher loads, or lower viscosity lubricants, by using dimples

3.5.2 Textured surfaces containing solid lubricants. Most of the work on dimpling and other textures has been aimed at liquid lubricated surfaces; however, a few experiments were conducted at ORNL in which a powdered lubricant was burnished onto a LST ceramic to see whether filling the shallow depressions would reduce friction. Figure 9 shows a surface of laser-dimpled TTZ in which graphite was burnished into the dimples before the specimen was rubbed against a steel counterface. Compared with non-dimpled surfaces, the solid lubricant delayed the onset of frictional transitions to higher levels. However, as is evident in Figure 9, the benefits of graphite impregnation were limited in duration and eventually were overtaken by the production of tribo-oxidation products from the slider (rust colored debris).

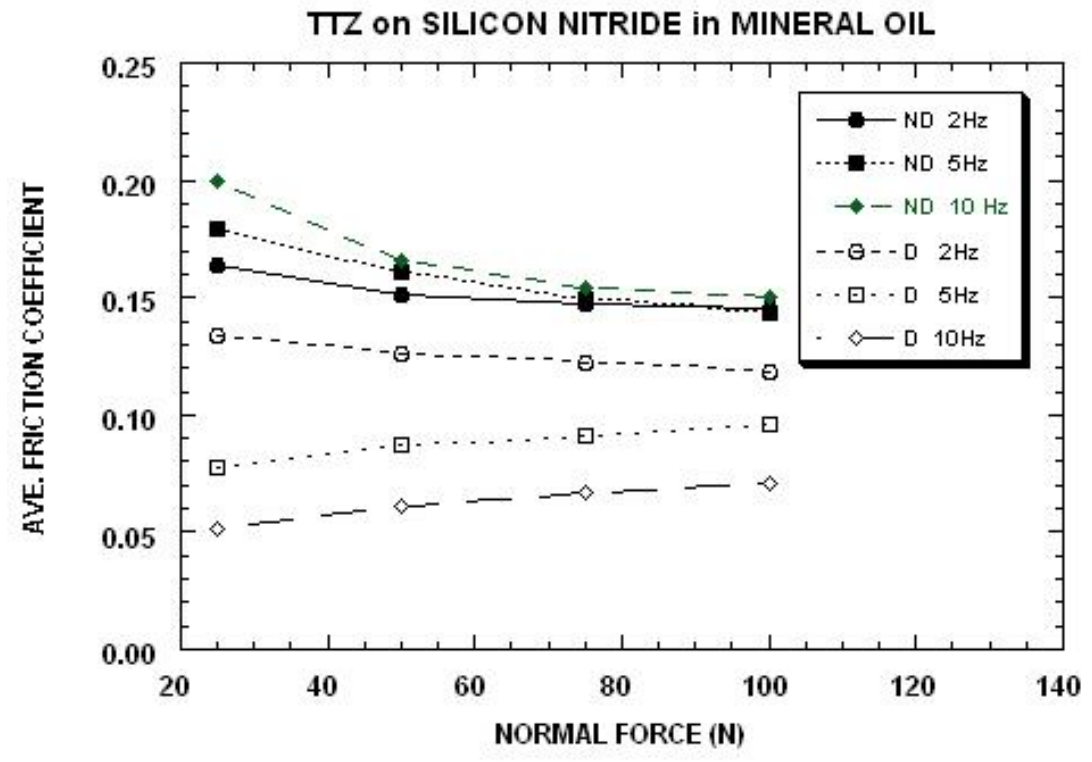

Figure 7. Effects of oscillating frequency and normal force on a mineral oil-lubricated ceramic sliding couple. $\mathrm{ND}=$ no dimples, $\mathrm{D}=$ laser dimpled. [37] 


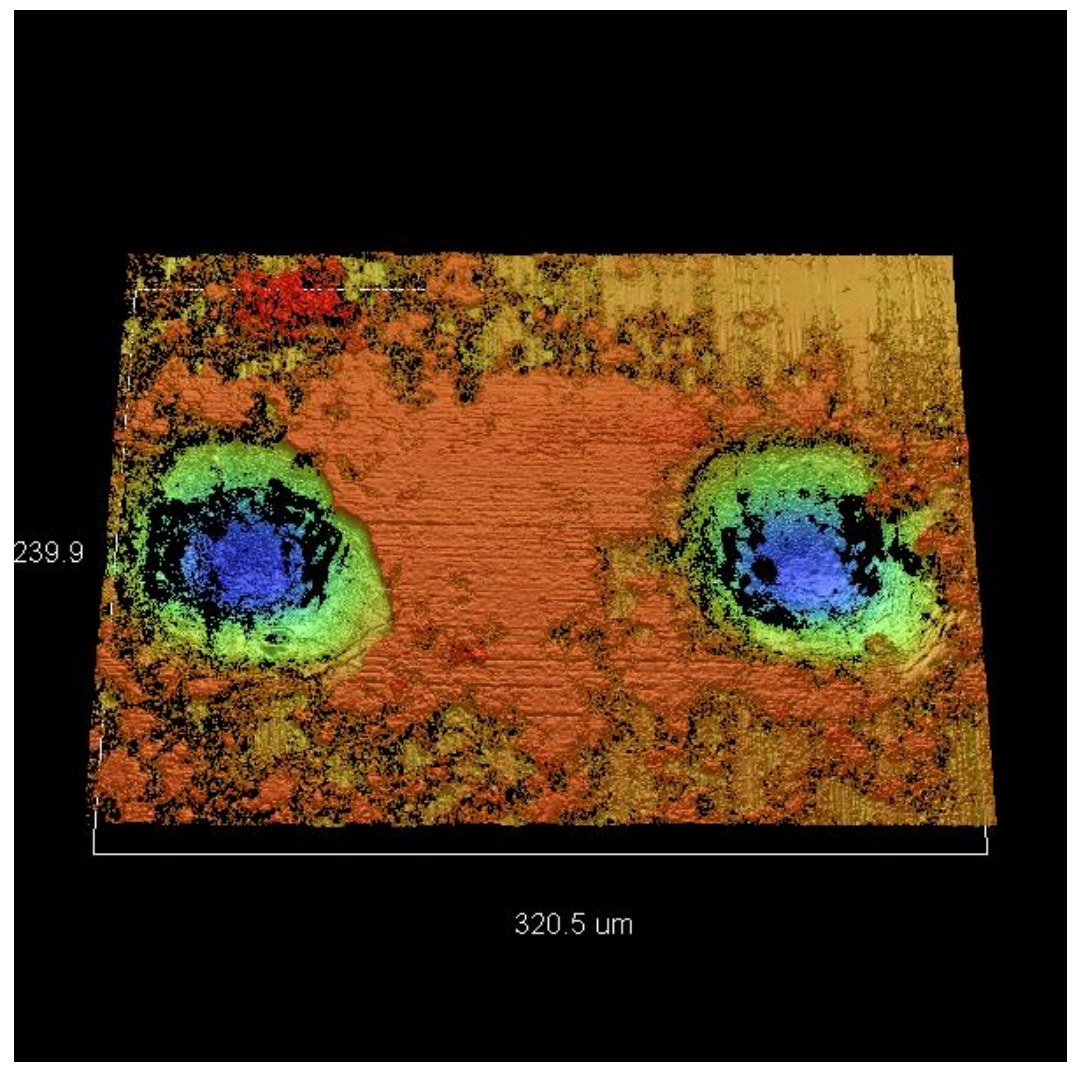

Figure 8. Dimples in zirconia after wear testing in mineral oil. Counterface wear debris, raised higher than the original surface, adheres to regions between and around the dimples.

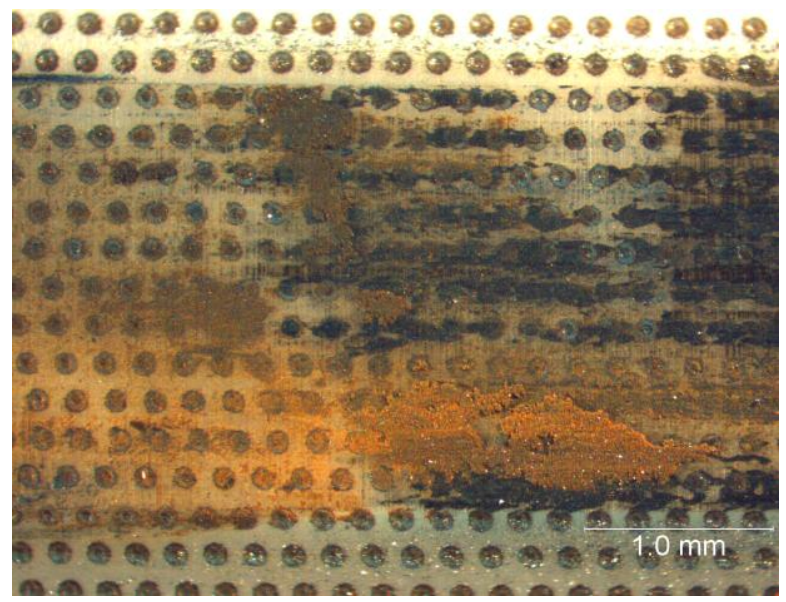

Figure 9. Experiments in which the laser dimples in ceramics were filled with graphite lubricant. Eventually, oxide wear debris from the steel slider masked the effects of the graphite-filled dimples. 
3.6 Modeling efforts. Much of the early work on surface texturing consisted of experimental or empirical studies, but with the advent of more advanced computers models have been developed to explore the effects of various textures on lubrication $[10,40]$.

In prior work, Wang et al. [2] had investigated how the shapes and aspect ratios of elliptical cavities would affect the film thickness and regime of lubricating over a range of dimple geometries, loads, and speeds.

3.7 Surface engineering with a textural component. Surface engineering, in the context of tribology, includes any and all finishing processes, treatments, or coatings that can be applied to bearing surfaces to improve their functional performance. Therefore, texturing can be combined with other processes like surface treatment and coatings, offering a host of additional options to improve friction and wear behavior, especially in bearings whose designs are amenable to texturing.

\section{Conclusions}

Decades of work on the texturing of bearing surfaces has taken many forms. Depending on the configuration of the features, the materials involved, the alignment of the sliding surfaces, the type of relative motion, the speed of relative motion, the lubricant properties, and the design of the component, the effects of texturing have ranged from beneficial to undetectable to negative. Over a wide range of applications, the proper alignment of the mating surfaces is a key to realizing the beneficial effect of textures. That is why texturing effects are more easily realized in flat-on-flat face seals than for non-conformal contact geometries like piston rings on liners or shafts turning within sleeve bearings. The same alignment consideration holds true for experimental work. Situations where the sliding speed or load changes periodically can disrupt lubricant films and conceal the potentially beneficial effects of texturing.

Recent research is showing that control of the shapes (or various combinations of shapes) and the orientation of features in regard to the direction of relative motion can affect the degree to which texturing will reduce friction. Therefore, the proper selection of texture shapes, sizes, spacings, and orientation is essential to using textures to enhance the performance of lubricated contacts. Some methods used to produce textures can create residual artifacts that need to be removed. That adds another cost element to the economics of surface engineering using texture patterns. Experimental work on texture evaluation must be properly simulated to enable valid screening of candidate textures for specific applications.

(Note: Appendix 1 presents a compilation of prior work on surface texturing, sorted by topic area. Some articles are aimed at specific components while others are of a more generic or fundamental research nature. There is some overlap with the References below.) 


\section{References}

1 M. M. Khonsari and E. R. Booser (2001) Applied Tribology: Bearing Design and Lubrication, Wiley and Sons, NY, p. 66.

2. Q. J. Wang, D. Zhou, R. Zhou., and F. Hashimoto (2008) Investigating the Effect of Surface Finish on Mixed EHL in Rolling and Rolling-Sliding Contacts, Trib. Trans., Vol. 51, pp. 748-761.

3. International Energy Agency (IEA), Annex IV, Cooperative Program on Integrated Engineered Surface Technology, http://www.iea-ia-amt.org/annexIV.htm (accessed June 2011)

4. I. Etsion (2004) Improving Tribological Performance of Mechanical Components by Laser Surface Texturing. Tribology Letters, Vol. 17, pp. 733-737.

5. J. C. Bierlein (1975) The Journal bearing, Scientific American, July, pp. 50-52 and 57-64.

6. M. E. Salama (1950) Effect of macro-roughness on the performance of parallel thrust bearings, Proc. I. Mech. Engr., Vol. 163, pp. 149-161.

$7 \quad$ Y. Kumada, K. Hashizume, S. Kamiya (1996) Euro Patent EP 19950912448.

$8 \quad$ N. Zirkelback and L.S. Andres (1998) Finite Element Analyis of Herringbone Groove Journal Bearings: A Parametric Study, J. of Tribology, Vol. 120(2), pp. 234-241.

9 R. J. Hensel (1995) Fluid Bearing with Asymmetrical Groove Pattern, U.S. Patent 5,427,456.

10. Y. Qiu and M. M. Khonsari (2011) Performance Analysis of Full-Film Textured Surfaces with Consideration of Roughness Effect," ASME J. of Tribology, Vol. 133, pp. 021704-1 to 021704-10.

11 S. loannides (2001) Dimpled bearings run smoother, longer, Machine Design.com, Nov. 8, online.

12 M. Ito, K. Kaneda, I. Nishimura,K. Yasuda, and R. Matsuno (2000) Reduction of polyethylene wear by concave dimples on the frictional surface in artificial hip joints, J. of Arthroplasty, Vol. 15 (3) pp 332-338.

13 ESKA Australia PTY Ltd., NSW, Australia.

14 T. S. Kustandi, J. H. Choo, H. Y. Low, and S. K Sinha (2010) Texturing of UHMWPE surface via NIL for low friction and wear properties, J. Appl. Phys D: Applied Phys., Vol. 43, pp. 1-6.

15 L. M. Gao, Q. E. Meng, F. Liu, J. Fisher, and Z. M. Jin (2010) The effect of aspherical geometry and surface texturing on the elastohydrodynamic lubrication of metal-on-metal hip prostheses under physiological loading and motions, Proc. I. Mech E., Vol. 224 (C: Mech. Engr. Sci.), Paper JMES2193, pp. 2627-2636.

L. M. Gao, L. M.,P. Yang, P., I. Dymond, J. Fisher, and Z. M. Jin (2010) Effect of surface texturing on the elastohydrodynamic lubrication analysis of metal-on-metal hip implants. Tribol. Int.. Vol. 43 (10), pp. 1851-1860.

17 S. A. McKee (1927) Effect of abrasive in lubricant, Soc. of Auto. Engr., Vol. 20, pp. 3-6.

18 J. A. Williams and A. M. Hyncica (1992) Mechanisms of abrasive wear in lubricated contacts, Wear, Vol. 152(1), pp. 57-74.

19 N. P. Suh (1986) Tribophysics, Prentice Hall, Englewood Cliffs, NJ, pp. 141-172.

20 N. Saka, H. Tian, and N. P. Suh (1989) Boundary Lubrication of Undulated Metal Surfaces at Elevated Temperatures, Tribology Transactions, 32(3), pp. 389-385.

21 H. Tian, N. Saka, and N. P. Suh (1989) Boundary Lubrication Studies on Undulated Titanium Surfaces, Tribology Transactions, 32(3), pp. 289-296.

22 N. P. Suh, M. Mosleh, and P. S. Howard (1994) Control of friction, Wear, Vol. 175, pp. 151-158.

23 A. Volchok, G. Halperin and I. Etsion (2002) The Effect of Surface Regular Micro-Topography on Fretting Fatigue Life, Wear, 253, Aug. 2002, pp.509-515.

24 J. Sep and A. Kucaba-Pietal (2001) Experimental testing of journal bearings with two-component surface layer in the presence of an oil abrasive contaminant, Wear, Vol. 249, pp. 1090-1095. 
L. Zhou, M. Beck, H. H. Gatzen, K. J. Altshuler, and F. E. Talke (2005) Slider vibration reduction using slider surface texture, Microsystems Tech., Vol. 11, pp. 857-866.

26 U. Pettersson and S. Jacobson (2003), "Influence of Surface Texture on Boundary Lubricated Sliding Contacts," Tribol. Int., Vol. 36 (11), pp. 857-864.

27 X. Wang, K. Kato, K. Adachi, and K. Aizawa (2001) The effect of laser texturing of SiC surface on the critical load for the transition of water lubrication mode from hydrodynamic to mixed, Trib. Intl., Vol. 34, pp. 703-711.

28 L. Zhou, K. Kato, N. Umehara, and Y. Miyake (1999) Nanometre scale island-type texture with controllable height and area ratio formed by ion beam etching on hard-disk head sliders, Nanotech., Vol. 10, pp. 363-372.

29 T. Sakai, N. Nedyalkov and M. Obara (2007) Friction characteristics of submicrometre-structured surfaces fabricated by particle-assisted near-field enhancement with femtosecond laser, J. Phys. D: Appl. Phys., Vol. 40, pp. 7485-7491.

30 S. M.Hsu (2003) An Integrated Approach to Design Intelligent Surfaces for Heavily Loaded Contacts, prese. at the ASME/STLE Joint Tribology Conference, Ponte Vedra, FL.

31 Wakuda, M., Yamauchi, Y., Kanzaki, S., and Yasuda, Y. (2003) Effect of Surface Texturing on Friction Reduction Between Ceramic and Steel Materials under Lubricated Sliding Contact, Wear, Vol. 254, pp. 356-363.

32 M. Nakano, A. Korenaga, A. Korenaga, K. Miyake, T. Murakami, Y. Ando, H. Usami and S. Sasaki (2007) Applying Micro-Texture to Cast Iron Surfaces to Reduce the Friction Coefficient Under Lubricated Conditions, Tribology Lett., Vol. 28 (2), pp. 131-137.

33 S. Yuan, W. Huang, and X. Wang (2011) Orientation effects of micro-grooves on sliding surfaces, Trib. Intern., Vol. 44, pp. 1047-1054.

34 L. M. Vilhena, B. Podgornik, J. Vizintin, and J. Mozina (2011) Influence of texturing parameters and contact conditions on tribological behavior of laser textured surfaces, Meccanica, Vol. 46, pp. 567-575.

35 E.-S. Yoon, R. A. Singh, H. Kong, B. Kim, D.-H. Kim, H. E. Jeong, and K. Y. Suh (2006) Tribological properties of bio-mimetic nano-patterned polymeric surfaces on silicon wafer, Trib. Lett., Vol. 21 (1), pp 31-37.

L. Zhou, K. Kato, G. Vurens, and F. E. Talke (2003) The effect of slider surface texture on the flyability and lubricant migration under near-contact conditions, Tribol. Intl., Vol. 36 (4-6), pp. 269-277.

37 P. J. Blau (2003) Challenges for the Application of Engineered Surfaces to Tribosystems Subjected to Multiple Contact Modes, presentation at the Joint ASME/STLE International Tribology Conference, Ponte Vedra, FL, October 28.

38 A. Kovalchenko, O. Ajayi, A. Erdemir, G. Fenske, and I. Etsion (2004) The Effect of Laser Texturing of Steel Surfaces and Speed-Load Parameters on the Transition of Lubrication Regime from Boundary to Hydrodynamic. Tribology Transactions, Vol. 47 (2), pp. 299-307.

39 A. Kovalchenko, O. Ajayi, A. Erdemir, G. Fenske, and I. Etsion (2005) The Effect of Laser Surface Texturing on Transition in Lubrication Regimes During Unidirectional Sliding Contact. Tribology International, Vol. 38, pp. 219-225.

40 Q. J. Wang and D. Zhou (2005) Virtual Texturing: Modeling the Performance of Lubricated Contacts of Engineered Surfaces, J. of Trib., Vol. 127(4), pp. 722-728. 
Appendix 1

\section{Basic and Applied Research on Texturing for Improved Friction and Wear}

\begin{tabular}{|c|c|}
\hline Topics & Table Reference \\
\hline \multicolumn{2}{|l|}{ 1) Basic Studies } \\
\hline Texturing of dry surfaces - debris control & $\mathrm{A} 15, \mathrm{~A} 16, \mathrm{~A} 51, \mathrm{~A} 62$ \\
\hline $\begin{array}{l}\text { Modeling of texture effects on lubrication and lubrication } \\
\text { regimes }\end{array}$ & $\begin{array}{l}\text { A6, A11, A12, A19, A24, A35, A36, A38 } \\
\text { A41, A44, A53, A54, A55, A58, A60, } \\
\text { A64, A69 }\end{array}$ \\
\hline \multicolumn{2}{|l|}{ 2) Applications } \\
\hline Effects of grooves on plain bearings & A3, A52, A58 \\
\hline Texturing of bio-implants & A59 \\
\hline Texturing of computer media & $\mathrm{A} 2, \mathrm{~A} 32, \mathrm{A33}, \mathrm{A34}, \mathrm{A49}$ \\
\hline Texturing of face seals and thrust bearings & $\begin{array}{l}\text { A1, A4, A5, A8, A9, A11, A12, A14, A17, } \\
\text { A18, A27, A31, A55, A64, A69 }\end{array}$ \\
\hline Texturing of metal sheet for improved forming & A65 \\
\hline Texturing of internal combustion engine components & $\begin{array}{l}\text { A3, A7, A10, A13, A25, A29, A30, A37, } \\
\text { A56 }\end{array}$ \\
\hline Texturing of rolling elements & A63, A71 \\
\hline \multicolumn{2}{|l|}{ 3) Processes } \\
\hline Texturing by electro-discharge machining & A65 \\
\hline Texturing by laser dimpling & $\begin{array}{l}\text { A7, A8, A10, A11, A13 - A41, A64, A68, } \\
\text { A70 }\end{array}$ \\
\hline Texturing by vibratory contact or other machining & $\mathrm{A} 46, \mathrm{~A} 47, \mathrm{~A} 50, \mathrm{~A} 61, \mathrm{~A} 63$ \\
\hline Texturing by indentation arrays & A67 \\
\hline Texturing by abrasive jets & $\mathrm{A} 43, \mathrm{~A} 50$ \\
\hline Texturing by masking or etching methods & $\mathrm{A} 42, \mathrm{~A} 44, \mathrm{~A} 45, \mathrm{~A} 48, \mathrm{~A} 57, \mathrm{~A} 62, \mathrm{~A} 66$ \\
\hline
\end{tabular}

\section{Appendix 1 References}

A1 M. E. Salama (1950) Effect of macro-roughness on the performance of parallel thrust bearings, Proc. I. Mech. Engr., Vol. 163, pp. 149-161.

A2 R. Ranjan, D. N. Lambeth, M. Tromel, P. Goglia, and Y. Li (1991) "Laser texturing for low-flyingheight media," J. of Appl. Phys, Vol. 69 (8), pp.5745-5747.

A3 Y. Kumada, K. Hashizume, and Y. Kimura (1996) Performance of Plain Bearings with Circumferential Grooves, Trib. Trans., Vol. 39(1), pp 81-86.

A4 C. M. Allen, J. N. Anno, and J. A. Walowit (1969) "Load support and leakage from microasperitylubricated face seals, developing hydrodynamic lubricant films," J. of Lubr. Tech., Vol. 91, pp 726-731.

A5 W-T. Lai (1993) “Face Seal with Double Spiral Grooves (1993) U.S. Patent 5,201,531.

A6 Q. J. Wang, D. Zhou, R. Zhou, and E. Hashimoto (2008) Investigating the Effect of Surface Finish on Mixed EHL in Rolling and Rolling-Sliding Contacts, Trib. Trans, Vol. 51, pp 748-761.

A7 A. Ronen, I. Etsion and Y. Kligerman (2001) Friction-Reducing Surface Texturing in Reciprocating Automotive Components, Tribology_Transactions, Vol. 44, No. 3, pp. 359-366.

A8 I. Etsion and G. Halperin (2002) A Laser Surface Textured Hydrostatic Mechanical Seal. Tribology Transactions, Vol. 45, No. 3, pp. 430-434. 
I. Etsion and L. Burstein (1996) A Model for Mechanical Seals with Regular Microsurface Structure. Tribology Transactions, Vol. 39, No. 3, pp. 677-683.

A10 G. Ryk, Y. Kligerman and I. Etsion (2002) Experimental Investigation of Laser Surface Texturing for Reciprocating Automotive Components. Tribology Transactions, Vol.45, No. 4, Oct. 2002, pp. 444-449.

A11 I. Etsion, Y. Kligerman and G. Halperin (1999) Analytical and Experimental Investigation of LaserTextured Mechanical Seal Faces. Tribology Transactions, Vol. 42, No. 3, pp. 511-516.

A12 Y. Kligerman and I. Etsion (2001) Analysis of the Hydrodynamic Effects in a Surface Textured Circumferential Gas Seal. Tribology Transactions, Vol. 44, No. 3, pp. 472-478.

A13 A. Ronen, I. Etsion and Y. Kligerman (2001) Friction-Reducing Surface Texturing in Reciprocating Automotive Components. Tribology Transactions, Vol. 44, No. 3, pp. 359-366.

A14 I. Etsion and G. Halperin (2002) A Laser Surface Textured Hydrostatic Mechanical Seal. Tribology Transactions, Vol. 45, No. 3, pp. 430-434.

A15 M. Varenberg, G. Halperin and I. Etsion (2002) Different Aspects of the Role of Wear Debris in Fretting Wear, Wear, Vol. 252, pp. 902-910.

A16 A. Volchok, G. Halperin and I. Etsion (2002) The Effect of Surface Regular Micro-Topography on Fretting Fatigue Life. Wear, 253, pp.509-515.

A17 S. Pride, K. Folkert, P. Guichelaar, and I. Etsion (2002) Effect of Micro-Surface Texturing on Breakaway Torque and Blister Formation on Carbon-Graphite Faces in a Mechanical Seal. Lubrication Engineering Vol. 58, No. 10, pp. 16-21.

A18 V. Brizmer, Y. Kligerman and I. Etsion (2003) A Laser Surface Textured Parallel Thrust Bearing, Tribology Transactions, Vol. 46, No. 3, pp. 397-403.

A19 A. Kovalchenko, O. Ajayi, A. Erdemir, G. Fenske, and I. Etsion (2004) The Effect of Laser Texturing of Steel Surfaces and Speed-Load Parameters on the Transition of Lubrication Regime from Boundary to Hydrodynamic, Tribology Transactions, Vol. 47, No. 2, pp. 299-307.

A20 Etsion, G. Halperin, V. Brizmer and Y. Kligerman (2004) Experimental Investigation of Laser Surface Textured Parallel Thrust Bearings. Tribology Letters, Vol. 17, pp 295-300.

A21 A. D. McNickle and I. Etsion (2004) Near Contact Laser Surface Textured Dry Gas Seals. J. of Tribology, Trans. ASME, Vol. 126, pp. 788-794.

A22 I. Etsion (2004) Improving Tribological Performance of Mechanical Components by Laser Surface Texturing. Tribology Letters, Vol. 17, Nov. 2004, pp. 733-737.

A23 I. Etsion (2005) State of the Art in Laser Surface Texturing. J. of Tribology, Trans. ASME, Vol. 127, pp. 248-253.

A24 A. Kovalchenko, O. Ajayi, A. Erdemir, G. Fenske, and I. Etsion (2005) The Effect of Laser Surface Texturing on Transition in Lubrication Regimes During Unidirectional Sliding Contact. Tribology International, Vol. 38, pp. 219-225.

A25 Y. Kligerman, I. Etsion and A. Shinkarenko (2005) Improving Tribological Performance of Piston Rings by Partial Surface Texturing. J. of Tribology, Trans. ASME, Vol. 127, No. 3, pp. 632-638.

A26 G. Ryk, Y. Kligerman, I. Etsion, and A. Shinkarenko (2005) Experimental Investigation of Partial Laser Surface Texturing for Piston Rings Friction Reduction. Tribology Transactions, Vol. 48, No. 4, pp. 583-588.

A27 Y. Feldman, Y. Kligerman and I. Etsion (2006) A Hydrostatic Laser Surface Textured Gas Seal, Tribology Letters, Vol. 22, No. 1, pp. 21-28.

A28 Y. Feldman, Y. Kligerma, I. Etsion, and S. Haber (2006) The Validity of the Reynolds Equation in Modeling Hydrostatic Effects in Gas Lubricated Textured Parallel Surfaces. J. of Tribology, Trans. ASME, Vol. 128, No. 2, pp. 345-350. 
A29 G. Ryk and I. Etsion (2005) Testing Piston Rings with Partial Laser Surface Texturing for Friction Reduction. Tribology Transactions, Vol. 48, No. 4, pp.583-588.

A30 I. Etsion, G. Halperin, and E. Becker (2006) The Effect of Various Surface Treatments on Piston Pin Scuffing Resistance. Wear, Vol. 261, pp. 785-791.

A31 Y. Feldman, Y. Kligerman and I. Etsion (2007) Stiffness and Efficiency Optimization of a Hydrostatic Laser Surface Textured Gas Seal, J. of Tribology, Trans. ASME, Vol. 127, pp. 407-410.

A32 B. Raeymaekers, I. Etsion, and F. E. Talke (2007) Enhancing Tribological Performance of the Magnetic Tape/Guide Interface by Laser Surface Texturing, Tribology Letters, Vol. 27, April 2007, pp. 89-95.

A33 B. Raeymaekers, I. Etsion, and F. E. Talke (2007) A Model for Magnetic Tape/Guide Friction Reduction by Laser Surface Texturing, Tribology Letters, Vol. 28, pp. 9-17.

A34 A.N. Murthy, I. Etsion, and F.E. Talke (2007) Analysis of Surface Textured Air Bearing Sliders with Rarefaction Effects, Tribology Letters, Vol. 28, No. 3, pp. 251-261.

A35 L. Rapoport, A. Moshkovich, V. Perfilyev, I. Lapsker, G. Halperin, Y. Itovich, and I. Etsion (2008) Friction and Wear of MoS2 Films on Laser Textured Steel Surfaces, Surface and Coatings Technology, Vol. 202, No. 14, pp. 3332-3340.

A36 A. Shinkarenko, Y. Kligerman, and I. Etsion (2009) The Effect of Surface Texturing in Soft ElastoHydrodynamic Lubrication, Tribology International, Vol. 42, No. 2, pp. 284-292.

A37 I. Etsion and E. Sher (2009) Improving Fuel Efficiency with Laser Surface Textured Piston Rings, Tribology International, Vol. 42, No. 4, pp. 542-547.

A38 A. Shinkarenko, Y. Kligerman, and I. Etsion (2009) The Validity of Linear Elasticity in Analyzing Surface Texturing Effect for Elasto-Hydrodynamic Lubrication, J. of Tribology, Trans. ASME, Vol. 131, No.2, paper 021503

A39 L. Rapoport, A. Moshkovich, V. Perfilyev, A. Gedanken, Yu. Koltypin, E. Sominski, G. Halperin, and I. Etsion (2009) Wear life and adhesion of solid lubricant films on laser-textured steel surfaces, Wear, Vol. 267 (5-8), pp. 1203-1207.

A40 A. Shinkarenko, Y. Kligerman, and I. Etsion (2009) The Effect of Elastomer Surface Texturing in Soft Elasto-Hydrodynamic Lubrication, Tribology Letters, Vol. 36 (2), pp. 95-103.

A41 A. Shinkarenko, Y. Kligerman, and I. Etsion (2010) Theoretical Analysis of Surface Textured Elastomer Sleeve in Lubricated Rotary Sliding, Tribology Transactions, Vol. 53 (3), pp. 376-385.

A42 N. P. Suh (1986) Tribophysics, Prentice Hall, Englewood Cliffs, NJ.

A43 Wakuda, M., Yamauchi, Y., Kanzaki, S., and Yasuda, Y., 2003, "Effect of Surface Texturing on Friction Reduction Between Ceramic and Steel Materials under Lubricated Sliding Contact," Wear, 254, pp. 356-363.

A44 N. Saka, H. Tian, and N. P. Suh (1989) Boundary Lubrication of Undulated Metal Surfaces at Elevated Temperatures, Tribology Transactions, 32, No. 3, pp. 389-385.

A45 H. Tian, N. Saka, and N. P. Suh (1989) Boundary Lubrication Studies on Undulated Titanium Surfaces, Tribology Transactions, 32, No. 3, pp. 289-296.

A46 V. P Bulatov, V. A. Krasny, and Y. G. Schneider (1997) Basics of Machining Methods to Yield Wear and Fretting Resistive Surfaces, Having Regular Roughness Patterns," Wear, 208, pp. 132-137. ('vibrorolling')

A47 Y. Uehara, M. Wakuda, Y. Yamaguhi, S. Kanzaki, and S. Sakaguchi (2004) Tribological properties of dimpled silicon nitride under oil lubrication, J. of the Euro. Ceramic Soc., Vol. 24(2), 369-373.

A48 R. Srinivasan and V. Mayne-Banton (1982) Self-developing photo-etching of poly(ethylene terephtalate) films by far-ultraviolet excimer laser radiation, Appl. Phys. Lett., Vol. 41, pp. 576578. 
A49 R. Ranjan, D. N. Lambeth, M. Tromel, P. Goglia, and Y. Li (1991) Laser texturing for low flying height media, J. Appl. Phys., Vol. 69, No. 8, pp. 5745-5747.

A50 M. Nakano, A. Korenaga, A. Korenaga, K. Miyake, T. Murakami, Y. Ando, H. Usami and S. Sasaki (2007) Applying Micro-Texture to Cast Iron Surfaces to Reduce the Friction Coefficient Under Lubricated Conditions, Tribology Lett., Vol. 28, No. 2, pp. 131-137.

A51 P. L. Menezes, K. Kailas, and S. Kailas (2006) Influence of surface texture on coefficient of friction and transfer layer formation during sliding of pure magnesium pin on $080 \mathrm{M} 40$ (EN8) steel plate, Wear, Vol. 261 (5-6), pp. 578-591.

A52 N. Tala-ighil, P. Maspeyrot, M. Fillon, and A. Bounif (2007) Effects of surface texture on journalbearing characteristics under steady-state operating conditions, Proc Inst Mech. Engr. (J), vol. 221(6), pp. 623-633.

A53 Q. J. Wang and D. Zhou (2005) Virtual Texturing: Modeling the Performance of Lubricated Contacts of Engineered Surfaces, J. of Trib., Vol. 127(4), pp. 722-728.

A54 X. Wang, K. Kato, K. Adachi, and K. Aizawa (2001) The Effect of Laser Texturing of SiC Surface on the Critical Load for the Transition of Water Lubrication Mode from Hydrodynamic to Mixed, Tribol. Intl., Vol. 34, pp. 703-711.

A55 G.C. Buscaglia, I. Ciuperca, M. Jai (2005) The effect of periodic textures on the static characteristics of thrust bearings, J. Tribol., Vol. 127(4), pp. 899-903.

A56 R. Takata, Y. Li, V. W. Wong (2006) Effects of Liner Surface Texturing on Ring/Liner Friction in Large Bore IC Engines, Proceedings of ASME Internal Combustion Engine Division 2006 Fall Technical Conference, paper number ICEF2006-1525.

A57 X. Wang, W. Liu, F. Zhou, and D. Zhu (2009) Preliminary investigation of the effect of dimple size on friction in line contacts, Tribology Intern., Vol. 42, No. 7, pp. 1118-1123.

A58 N. Zirkelback and L.S. Andres (1998) Finite Element Analyis of Herringbone Groove Journal Bearings: A Parametric Study, J. of Tribology, Vol. 120(2), pp. 234-241.

A59 M. Ito, K. Kaneda, I. Nishimura,K. Yasuda, and R. Matsuno (2000) Reduction of polyethylene wear by concave dimples on the frictional surface in artificial hip joints, J. of Arthroplasty, Vol. 15 (3) pp 332-338.

A60 L. M. Gao, Q. E. Meng, F. Liu, J. Fisher, and Z. M. Jin (2010) The effect of aspherical geometry and surface texturing on the elastohydrodynamic lubrication of metal-on-metal hip prostheses under physiological loading and motions, Proc. I. Mech E. Part C: Mech. Engr. Sci., Vol. 224 (Paper JMES2193), pp. 2627-2636.

A61 A. Greco, S. Raphaelson, K. Ehmann, Q. J. Wang, and C. Lin (2009) Surface Texturing of Tribological Interfaces Using the Vibromechanical Texturing Method, J. Manuf. Sci. and Engr., Vol. 131, pp. 061005-1 to 8.

A62 U. Pettersson and S. Jacobson (2003), Influence of Surface Texture on Boundary Lubricated Sliding Contacts, Tribol. Int., Vol. 36 (11), pp. 857-864.

A63 A. Greco, A. Martini, Y. Liu, C. Lin, and Q. J. Wang (2010) Rolling Contact Fatigue Performance of Vibro-Mechanical Textured Surfaces, Trib. Trans., Vol. 53, pp. 610-620.

A64 X. Wang, K. Kato, K. Adachi, and K. Aizawa (2001) The effect of laser texturing of SiC surface on the critical load for the transition of water lubrication mode from hydrodynamic to mixed, Trib. Intl., Vol. 34, pp. 703-711.

A65 R. Zhou, J. Cao, Q. J. Wang, F. Meng, K. Zimowksi, and Z. C. Xia (2011) Effect of electrical discharge texturing on tribological behavior of aluminum sheet, J. of Matl's Proc. Tech., Vol. 211, No. 10, pp 1643-1649. 
A66 L. Zhou, K. Kato, N. Umehara, and Y. Miyake (1999) Nanometre scale island-type texture with controllable height and area ratio formed by ion beam etching on hard-disk head sliders, Nanotech., Vol. 10, pp. 363-372.

A67 P. J. Blau (2010-12), research in progress at Oak Ridge National Laboratory, sponsored by the U.S. Department of Energy, Office of Vehicle Technologies.

A68 T. Sakai, N. Nedyalkov and M. Obara (2007) Friction characteristics of submicrometre-structured surfaces fabricated by particle-assisted near-field enhancement with femtosecond laser, J. Phys. D: Appl. Phys., Vol. 40, pp. 7485-7491.

A69 Y. Qiu and M. M. Khonsari (2011) Performance Analysis of Full-Film Textured Surfaces with Consideration of Roughness Effect," ASME J. of Tribology, Vol. 133, paper 021704.

A70 L. M. Vilhena, B. Podgornik, J. Vizintin, and J. Mozina (2011) Influence of texturing parameters and contact conditions on tribological behavior of laser textured surfaces, Meccanica, Vol. 46, pp. 567-575.

A71 S. loannides (2001) Dimpled bearings run smoother, longer, [www.Machine Design.com], Nov. 8, 2001, online. 